\title{
Instrumentation and method for high accuracy geo-referencing of sugar beet plants
}

\author{
M. Nørremark ${ }^{\text {a,* }}$, H.T. Søgaard ${ }^{\mathrm{b}}$, H.W. Griepentrog ${ }^{\mathrm{a}}$, H. Nielsen ${ }^{\mathrm{a}}$ \\ a Copenhagen University, Faculty of Life Sciences, Department of Agricultural Sciences, \\ Højbakkegaard Allé 2, DK-2630 Taastrup, Denmark \\ ${ }^{\mathrm{b}}$ Aarhus University, Faculty of Agricultural Sciences, Department of Agricultural Engineering, \\ Research Centre Bygholm, DK-8700 Horsens, Denmark
}

Received 4 April 2006; received in revised form 19 January 2007; accepted 22 January 2007

\begin{abstract}
Efficient use of automatic field operations will allow care and management of crops in very different systems from what is known today and may lead to the possibility of individual plant care systems. Automatic field operation systems have the potential to reduce environmental impact while preserving economics in crop production. These systems require accurate and reliable information about the position of individual crop plants and, if possible, additional information about crop growth status. The aim of the presented research was to generate a geo-spatial map of individual crop plants derived from geo-referenced data recorded during seeding operation. A standard sugar beet precision seeder was retrofitted with optical sensors that could detect seeds as they were released into the furrow. Furthermore, a real time kinematic global positioning system (RTK-GPS) and a dual axis tilt sensor provided the global position and attitude angles of the seeder. A data acquisition system was configured for recording and storage of global positions, seeder attitude data, and seed drop detections during seeding. This paper outlines the methodology of processing the recorded data into a geo-spatial seed map. The developed instrumentation was used in field experiments under typical conditions and operation velocities up to $5.3 \mathrm{~km} \mathrm{~h}^{-1}$. The validation showed that $95 \%$ of the sugar beet seedlings emerged within $37.3 \mathrm{~mm}$ from the seed drop positions contained in the geo-spatial seed map. An error analysis associated with the estimation of geo-referenced plant positions consisted of positioning sensor errors, seed displacement in the furrow and deviation between location of plant emergence and the corresponding seed location. Furthermore, the error contribution from individual sources was of the same magnitude, except for the error due to deviation between location of plant emergence and the corresponding seed location. As this fully random error will always occur, it was considered meaningless trying to further minimize the sensor errors. Inclusion of seeder attitude data in the data processing significantly improved the accuracy of the estimation of geo-referenced plant positions and therefore it was concluded that a dual axis tilt sensor should be a required part of the instrumentation. Furthermore, it was shown that high accuracy of the estimation of georeferenced plant positions required a zero horizontal velocity of the seed released from the seeding mechanism. In general, the overall accuracy of the estimation of geo-referenced plant positions was satisfactory to allow subsequent individual plant scale operations.
\end{abstract}

(C) 2007 Elsevier B.V. All rights reserved.

Keywords: Seed geo-referencing; Seeding technology; RTK-GPS

\footnotetext{
* Corresponding author. Tel.: +45 352 83560; fax: +45 35282175 .

E-mail address: mino@life.ku.dk (M. Nørremark).
} 


\section{Introduction}

Advances in computer power, sensors and electronics have led to a possibility of realising novel automated technologies for field operations (e.g. Bak and Jacobsen, 2004; Griepentrog et al., 2004; Kise et al., 2005; Lee et al., 1999). The need for such technologies is motivated by consumer and governmental demand for a reduction of pesticide and fertilizer usage in agriculture while preserving the economics in crop production. Pesticides and fertilizers are most often substituted by factors, such as increased management knowledge, new practices and techniques (Padel and Lampkin, 1994). Therefore, crop production with reduced agro-chemical inputs is generally considered as more labour intensive than conventional farming. A feasibility study by Sørensen et al. (2005) evaluated the impact of introducing automated technologies and procedures related to organic farming using two scenarios of weed control. The study focused on organic cultivated row crops, where hand weeding usually requires 100-300 ha hel (Melander and Rasmussen, 2001), and is thus financially more demanding. The evaluated automated technologies reduced labour demand by $83-85 \%$ in sugar beet and $60 \%$ in carrots. A drawback was that innovative technologies increased machine costs. Nevertheless, the study estimated an improvement of $72-85 \%$ to profitability on the assumption that sufficient weed control was provided by new technologies.

Efficient use of automatic field operations will allow care and management of crops in different systems from what is known today (e.g. Blackmore et al., 2005; Blasco et al., 2002; Cho et al., 2002; Sørensen et al., 2005; Van Zuydam et al., 1995). A field in which the crop is established in rows can be divided into three target areas where different application techniques for chemical or physical treatments are necessary: (i) the area between the rows (inter-row area), (ii) the area between the crop seedlings within the rows (intra-row area), and (iii) the area close to and around the crop seedlings (close-to-crop area). This may lead to the possibility of individual plant treatment systems providing potentially large savings in agro-chemicals with environmental and economic advantages (Blackmore et al., 2005; Griepentrog et al., 2003). These systems require accurate and reliable information about the position of crop plants and, if possible, additional information about the crop growth status. A highly accurate map of individual crop plants would allow several automatically controlled field operations such as (Ehsani et al., 2004; Griepentrog et al., 2005):

- guidance of vehicles (e.g. parallel to crop rows),

- guidance of implements or tools (e.g. physical inter-row and intra-row weeding),

- application of fluids or granules to individual crop plants (e.g. insecticides, fungicides, fertilizers, etc.) and

- measuring vigour and growth status of individual plants (e.g. spectral response and morphological properties).

Computer vision-based identification of the morphological shape of crop and weed seedlings have been studied and developed (Grundy et al., 2005; Lee et al., 1999; Søgaard and Nørremark, 2004; Søgaard, 2005). A drawback of computer vision in identifying crop seedlings under field conditions is that typically not more than $80 \%$ of the seedlings are recognized (Grundy et al., 2005; Lee et al., 1999). This is most often due to an overlap of crop and/or weed leaves. This result is not satisfying to allow automatic field operations. However, the rapid development of computer vision and data processing in real-time and in 3D is promising to overcome these problems (Andersen et al., 2005). Another approach is utilising a geo-spatial map of seeds to predict the positions of the crop seedlings within the images taken of each individual crop seedling (Søgaard and Nørremark, 2004). Accurate prediction of the positions of crop plants within images have contributed to improved reliability and efficiency of the recognition performance of the computer vision shape algorithm that identifies crop seedlings (Søgaard and Nørremark, 2004).

Agronomic potentials and technology for producing a geo-spatial map of individual crop seeds have been studied in the past (Ehsani et al., 2004; Griepentrog et al., 2003; Griepentrog et al., 2005; Nørremark et al., 2003). The aim of this paper, however, is to provide a thorough description and investigation of the instrumentation and methodology for producing high accurate geo-spatial map of individual sugar beet seeds from seeding operations, and to present new and improved results.

A two-step approach has been developed for producing the seed map: (i) during the seeding operation basic sensor data were recorded, and (ii) after the seeding operation the geo-referencing of individual seeds for the entire field were estimated by combining these sensor data (Griepentrog et al., 2005; Nørremark et al., 2003). Furthermore, the hypothesis is that by knowing where the seeds have been placed, crop plants can be individually located after emerging. The overall aim of the project was to create navigation information on which automatic technologies for physical weeding around individual crop plants or chemical treatments of individual crop plants could be based. 
The objectives of the presented research were:

(i) to equip a standard sugar beet seeder with a data acquisition system that could record time when seeds are dropped into the furrow and simultaneously record global positions and attitude angles of the seeder,

(ii) to develop data processing routines for the recorded data in order to compute a geo-spatial seed map,

(iii) to investigate the performance of the data acquisition system and data processing under different driving orientations, seed spacing and operation velocities, and

(iv) to determine sources of uncertainty and their magnitude.

\section{Materials and methods}

\subsection{Seeder}

A commercial six-row precision seeder for sugar beet was retrofitted with optical sensors for seed drop detection. Six infrared optical sensors (one per seeder unit) were mounted directly above the coulters to detect seeds when they drop into the furrows (Fig. 1). The sensor sensitivity range was adjusted by the seeder manufacturer to detect objects that are the size of seeds, and not dust particles. Trials in the lab, which checked the reliability of seed detection and cell filling, showed satisfying results for all operation velocities used in the field experiments (Griepentrog, 2001).

To minimize the displacement of seed from where it was dropped to where it remained and emerged, a seeder was chosen that releases seeds into the furrow with a relative horizontal velocity equal and opposite to the vehicle's forward velocity (Fig. 1). This technique is well known and machines with this feature achieve a higher evenness of longitudinal seed and plant spacing (Heege and Billot, 1999). Unfortunately, this was not the case for all seed spacing settings on the machine. Only one target spacing $(202 \mathrm{~mm})$ lead to zero horizontal velocity of the seed. Furthermore, the seeder was equipped with a V-shaped furrow opener. The V-shaped furrow opener assured uniform seed depth and minimised seed bouncing due to good seed-soil contact (Srivastava et al., 1993).

No modifications of the commercially available machine itself were made.

\subsection{Positioning system}

A real-time kinematic global positioning system (RTK-GPS) (Trimble Navigation Ltd., Sunnyvale, CA, USA) with an accuracy of about $\pm 20 \mathrm{~mm}$ was used to measure global positions. The system consisted of a Trimble MS7400 reference station and a Trimble MS750 mobile GPS unit connected via a Satel 3ASd FM radio link (Satel Oy, Salo, Finland). The correction signals provided by the reference station were transmitted to the mobile GPS unit once a second. A vertical rod with GPS antenna on top was attached to the centre of the seeder toolbar. The antenna height was $1.15 \mathrm{~m}$ above ground level and $0.75 \mathrm{~m}$ above the toolbar.

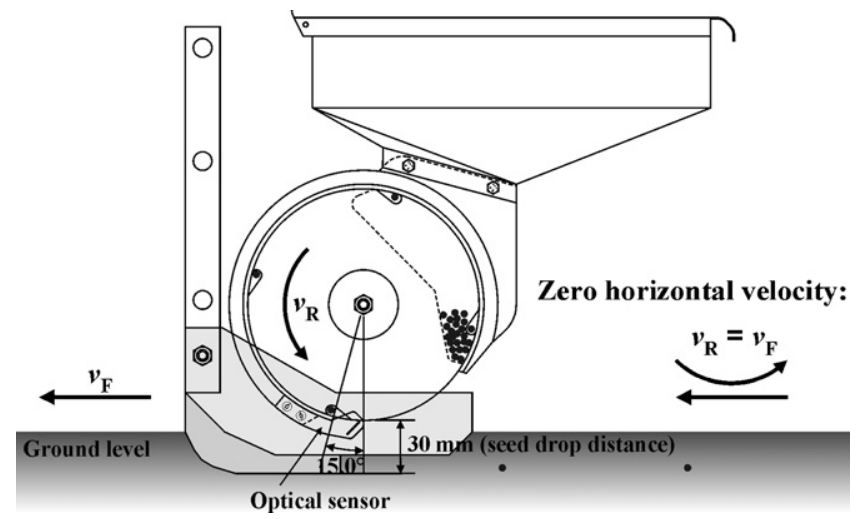

Fig. 1. Seeder unit layout, showing sensor location and the principle of zero horizontal velocity. Zero horizontal velocity is obtained when the relative horizontal velocity $\left(v_{\mathrm{R}}\right.$; relative to the vehicle) of the seed drop is equal and opposite to the vehicle forward velocity $\left(v_{\mathrm{F}}\right)$. The seed release angle is $15^{\circ}$ relative to horizontal. 
The data string 'NMEA-0183 PTNL, PJK' (PJK) was used for determining position (Trimble, 1999). The PJK data string contained the Coordinated Universal Time (UTC) of position computation, Northing, Easting, Altitude, positioning status and GPS quality. The positioning status referred to the potential positioning accuracy (i.e. RTK-GPS, DGPS or GPS) depending on the number of available satellites and the quality of reference station communication. The GPS quality referred to position dilution of precision (PDOP). PDOP values below 4.0 and a RTK-GPS positioning status were considered as fundamentals for the methodology of producing a geo-spatial map of individual seeds from seeding operations. The mobile GPS unit provided 20 PJK data strings per second via RS232. Furthermore, the mobile GPS unit was programmed to output individual ASCII data strings for UTC time tags at $1 \mathrm{~Hz}$, also via RS232 (Trimble, 1999). The UTC time tag strings provided the time within the GPS system. The mobile GPS unit also provided a digital pulse per second (PPS) which corresponded to each UTC second.

\subsection{Tilt sensor}

A TCM2-50 dual axis tilt sensor (Precision Navigation, CA, USA) was attached to the antenna rod in order to measure the attitude of the seeder during field operation. The sensor measured positive and negative pitch and roll relative to level in the range $-50^{\circ}$ to $+50^{\circ}$ with a resolution of $0.1^{\circ}$. The tilt sensor was programmed to output a partitioned ASCII dataset consisting of unfiltered sensor measurements of pitch and roll in degrees. The tilt sensor provided 20 dataset per second via RS232. Digital damping of sensor output was done by a low pass $n$-order finite impulse response (FIR) filter (moving average type, where $n=21$ ) with a cut off frequency at $0.4 \mathrm{~Hz}$. The digital damping is further described in subsequent sections on data processing.

\subsection{Data acquisition}

\subsubsection{Hardware}

The data logger consisted of a conventional DaqBook 120 (National Instruments, CA, USA). The DaqBook included amplifiers and conditioners which monitored digital pulses from optical seed sensors and PPS from the GPS. The acquisition rate was set to $200 \mathrm{~Hz}$. All data from the mobile GPS unit, dual axis tilt sensor and DaqBook were stored in a notebook computer. Fig. 2 shows a schematic diagram of the data acquisition system used.

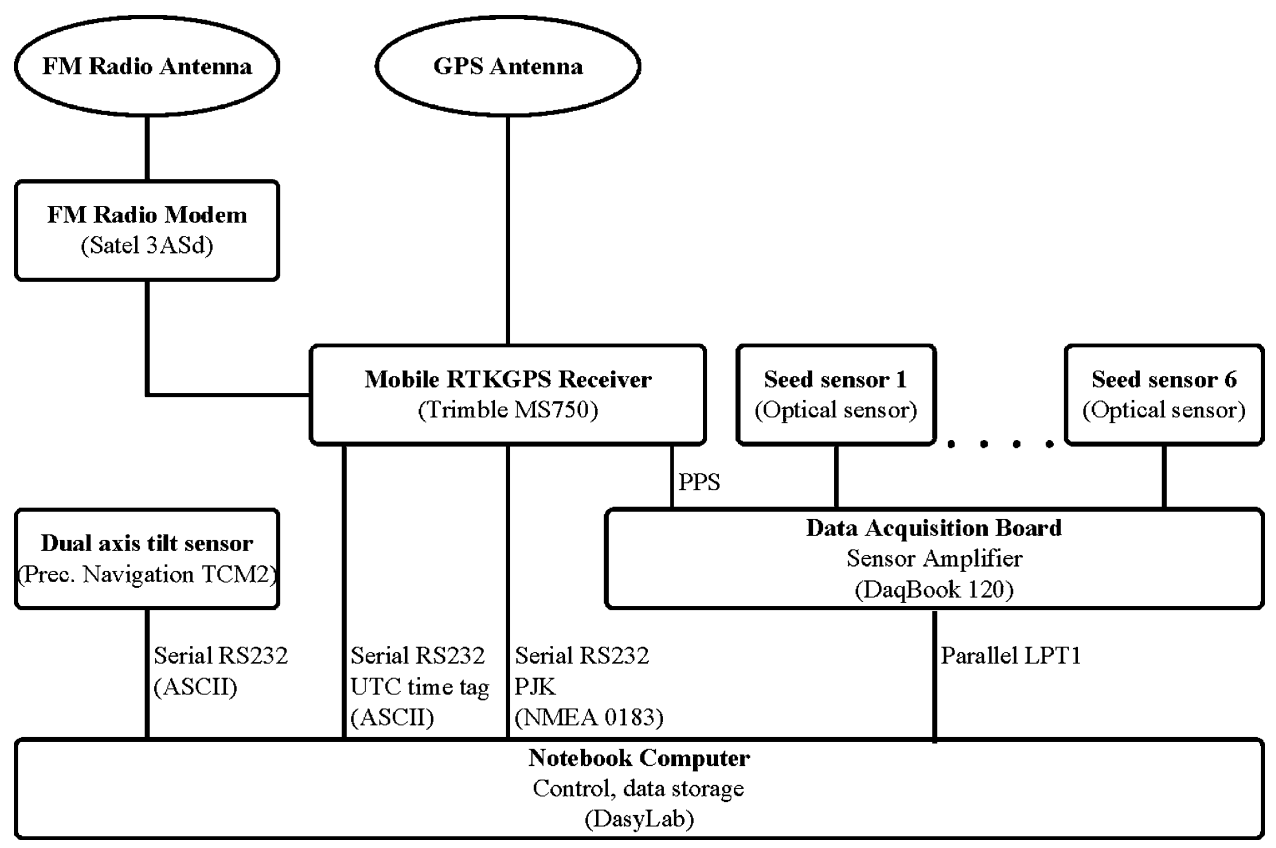

Fig. 2. Diagram of instrumentation. 


\subsubsection{Software}

The data acquisition software DASYLab (National Instruments, CA, USA) was used on the notebook to allow a flexible data management. All recorded data were stored directly in the notebook computer as ASCII strings with comma-separated values. Besides the sensor values each ASCII string also contained a data logger time tag derived from the DaqBook hardware clock (1 ms resolution). For each measuring session (i.e. from start to end of seeding operation), the software created a dataset consisting of individual files for: (i) GPS (PJK) data, (ii) UTC time tags, (iii) digital input from PPS detections, (iv) pitch and roll data, and (v) digital input from seed drop detections (one file per optical sensor). Each of the files contained the data logger hardware time tag in column one.

\subsection{Data processing}

The methodology of computing seed drop positions after seeding operation consisted of distinct steps of processing the acquired datasets. MATLAB ver. 6.5 (MathWorks, MA, USA) was used for the data processing procedures. Five main steps of data processing were used: (i) raw data treatment to remove GPS outliers, (ii) transformation of data logger hardware time tags into UTC time enabling synchronisation of tilt and seed drop detections with global position computation, (iii) determination of the interpolated global position and pitch and roll angle of the GPS antenna for each seed drop event, (iv) determination of the seeder heading at each seed drop event and (v) determination of the global position of the individual seeds by coordinate transformation.

\subsubsection{GPS data treatment}

The data processing was initialised by detecting and discarding global position outliers, i.e. position readings that were extreme in terms of distances between consecutive position readings. For each consecutive pair of horizontal position readings $\left(X_{i-1}, Y_{i-1}\right)$ and $\left(X_{i}, Y_{i}\right)$ of the GPS antenna location, the instantaneous velocity $v_{i}$ of the GPS antenna motions was computed as follows:

$$
v_{i}=\frac{\sqrt{\left(X_{i}-X_{i-1}\right)^{2}+\left(Y_{i}-Y_{i-1}\right)^{2}}}{\mathrm{UTC}_{i}-\mathrm{UTC}_{i-1}}, \quad i=2, \ldots, N
$$

where $N$ is the number of positions stored in the GPS data file, and $\mathrm{UTC}_{1}, \ldots, \mathrm{UTC}_{N}$ are the UTC time tags. A $z$-test was used to discard extreme positions. For each position a $z$-score determined the number of standard deviations between a given $v_{i}$ value and the average velocity derived from the past 20 positions. The formula for calculating the $z$-scores was as follows:

$$
z_{i}=\frac{v_{i+n}-s_{i}}{\sigma_{i} / \sqrt{n}}, \quad i=2, \ldots, N-n
$$

where $s_{i}$ was identical to the output from a low pass $n$-order FIR filter (moving average type, where $n=20$ ) with a cut off frequency at $0.4 \mathrm{~Hz}$ for digital damping of the velocity of GPS antenna motions. Note that raw data was not replaced by filtered data in this step.

$$
s_{i}=\frac{1}{n} \sum_{j=i}^{i+n-1} v_{j}, \quad i=2, \ldots, N-n
$$

$\sigma_{i}$ is the standard deviation of the moving average.

$$
\sigma_{i}=\sqrt{\frac{1}{n} \sum_{j=1}^{i+n-1}\left(v_{j}-s_{i}\right)^{2}}, \quad i=2, \ldots, N-n
$$

A position reading $\left(X_{i+n}, Y_{i+n}\right)$ was discarded if the absolute $z$-score $\left|z_{i}\right|$ was greater than $5(i=2, \ldots, N-n)$. After this operation, there were $N_{\mathrm{e}}$ positions left in the GPS data file. The discarding of some positions was compensated by an interpolation procedure that is described in subsequent sections. The discarding part was essential in situations where significant motions of the GPS antenna were recorded due to rapid changes of the seeder attitude.

\subsubsection{Transformation of data logger hardware time tags into UTC time}

The transformation was necessary because the reference time for global position computation was only in UTC time. It was therefore different from the time related to tilt and seed drop data, which were stored only with data logger 
hardware time as reference time. The transformation procedure involved ensuring that the leading edge of the digital PPS coincides with the beginning of each UTC second. Furthermore, PPS detections and simultaneous UTC time tags could be matched based on the data logger hardware time included in both data files. Let $t_{p}^{\prime}$ be the data logger hardware time value of the $p$ th recorded UTC time tag string, where $p=\{1, \ldots, K\}$, and $K$ is the total number of recorded strings. Furthermore, let $t_{p}^{\prime \prime}$ be the data logger hardware time values from the PPS file, where $q=\{1, \ldots, L\}$, and $L$ is the total number of recorded PPS. $K$ and $L$ were not always equal, which was due to the possibility of missing UTC time tag strings during start up of the data acquisition. Therefore, a nearest neighbour (NN) query was performed to pair PPS with corresponding UTC time tag strings. The nearest neighbour (NN) query estimated UTC as a function of $t_{p}^{\prime \prime}$ by retrieving the $\mathrm{UTC}_{p}$ value belonging to the $t_{p}^{\prime}$ value that was nearest to $t_{p}^{\prime \prime}$. Time delay measurements within the data-acquisition system showed that each UTC time tag string was received $0.79 \mathrm{~s}$ before its simultaneous PPS, and therefore this offset was subtracted from $t_{p}^{\prime \prime}$ before matching data logger hardware times. The equation for the nearest neighbour query was:

$$
\mathrm{UTC}_{q}^{\prime \prime}=\mathrm{UTC}_{p_{\mathrm{NN}}(q)}, \quad q=1, \ldots, L
$$

where $\mathrm{UTC}_{p}^{\prime \prime}$ is the estimated UTC that corresponds to the data logger hardware time $t_{p}^{\prime \prime}$ and

$$
p_{\mathrm{NN}}(q)=\underset{p}{\arg \min }\left|t_{p}^{\prime}-\left(t_{q}^{\prime \prime}-0.79\right)\right|, \quad q=1, \ldots, L
$$

The relationship between the vector of $\mathrm{UTC}_{p}^{\prime \prime}$ values and the vector of $t_{q}^{\prime \prime}$ was simplified to the following general linear relation between UTC and data logger hardware time $t$ :

$$
\mathrm{UTC}=t+c
$$

The parameter $c$ was the offset in seconds between the hardware indication of time and the UTC indication of time (determined as the average difference between $\mathrm{UTC}_{p}^{\prime \prime}$ and $t_{q}^{\prime \prime}$ values). The slope of the linear relation was set to 1 based on the assumption that the clock frequency for $t$ and UTC was equal. Eq. (7) was used in the subsequent steps of the data processing for synchronisation between UTC time-labelled global positions and data logger hardware time-labelled readings from the optical sensors and the tilt sensor.

\subsubsection{Determination of the interpolated global position and pitch and roll angle of the GPS antenna for each seed drop event}

Consider $t$ as any data logger hardware time where a seed drop event was detected by an optical sensor. The data processing then used the previous Eq. (7) to transform $t$ into a UTC time for the seed drop. Furthermore, let $\mathrm{UTC}_{h}$ be the UTC time tag of the $h$ th computed global position, where $h=\left\{1, \ldots, N_{\mathrm{e}}\right\}$, and $N_{\mathrm{e}}$ is the total number of global positions in the GPS data file (after discarding outliers). In order to link a single global position to the seed drop, a nearest neighbour approach was used. A nearest neighbour $(\mathrm{NN})$ query was performed to estimate Northing $(X)$, Easting $(Y)$ and altitude $(Z)$ as a function of the seed drop UTC time by retrieving the $X, Y$ and $Z$ values belonging to the $\mathrm{UTC}_{h}$ time that was nearest to the seed drop UTC time. The matching was done according to the minimum distance between $\mathrm{UTC}_{h}$ and UTC:

$$
h_{\mathrm{NN}}=\underset{h}{\arg \min }\left|\mathrm{UTC}_{h}-\mathrm{UTC}\right|
$$

A preliminary estimation of the global position and altitude at the seed drop event was then $X_{h}, Y_{h}$ and $Z_{h}$ for $h=h_{\mathrm{NN}}$, where $h_{\mathrm{NN}} \in\left\{1, \ldots, N_{\mathrm{e}}\right\}$. However, the estimated $X_{h}, Y_{h}$ and $Z_{h}$ for $h=h_{\mathrm{NN}}$ was only the nearest recorded global position and altitude to the seed drop event. Note that increased distance between recorded seeder positions was strongly correlated to increased forward velocity, e.g. distances exceeded $1 \mathrm{~cm}$ at operation velocity as low as $0.72 \mathrm{~km} \mathrm{~h}^{-1}$. Therefore, there was an obvious need for a step that interpolated an intermediate global position and altitude $(X, Y, Z)$ for the GPS antenna that corresponded to the actual seed drop event. A linear regression was applied to 10 positions before and after the nearest recorded position using the following three equations for $h=h_{\mathrm{NN}}$.

$$
\begin{aligned}
& X_{[h-10, h+10]}=v_{X} \mathrm{UTC}_{[h-10, h+10]}+k_{X} \\
& Y_{[h-10, h+10]}=v_{Y} \mathrm{UTC}_{[h-10, h+10]}+k_{Y}
\end{aligned}
$$




$$
Z_{[h-10, h+10]}=v_{Z} \mathrm{UTC}_{[h-10, h+10]}+k_{Z}
$$

The parameters of the linear regression models $\left(v_{X}, v_{Y}, v_{Z}, k_{X}, k_{Y}, k_{Z}\right)$ were estimated from data by least squares using a standard linear regression procedure of MATLAB ver. 6.5 (MathWorks, MA, USA). The linear regression models were used to determine the intermediate global position $(X, Y)$ and altitude $(Z)$ as a function of the seed drop time UTC. Thus, $X, Y$, and $Z$ represented the global position and altitude of the GPS antenna when the seed drop event took place.

Generally, for linear regression models needed for interpolation throughout the data post processing, 10 data points before and after a seed drop event was selected due to the fact that the linear models also provided low pass $n$-order FIR filters (moving average type where $n=21$ ) with a cut off frequency at $0.4 \mathrm{~Hz}$. The averaged middle data point of the moving average window (i.e. data point \#11) was not saved and original data was not replaced by filtered data.

The regression parameters $v_{X}$ and $v_{Y}$ in Eqs. (9) and (10) represent FIR filtered velocities in m s$~^{-1}$ along the Northing and Easting directions, respectively, at the actual seed drop event. Furthermore, the velocity $v$ of the antenna in $\mathrm{m} \mathrm{s}^{-1}$ at seed drop event was determined by:

$$
v=\sqrt{v_{X}^{2}+v_{Y}^{2}}
$$

Note that the discarding of outlier positions as mentioned previously was compensated by the interpolation procedures in Eqs. (9)-(11). The interpolation procedure assumes locally constant velocity in time and consequently, and was only valid for short term lack of position data. Short term lack of position data was a consequence of occasional discarding of global positions in conjunction to the GPS data treatment. The prerequisites for the processing of accurate seed drop positions were stable GPS communication and RTK-GPS mode of the receiver. The fulfilment of these prerequisites was supervised during seeding operations.

A nearest neighbour query approach was also used to predict the pitch $(\theta)$ and roll $(\phi)$ angles (in radians) at the seed drop event. Consider again $t$ as any data logger hardware time where a seed drop was detected by an optical sensor. Let $t_{j}^{\prime \prime \prime}$ be the data logger hardware time tag of the $j$ th pitch and roll reading, where $j=\{1, \ldots, M\}$, and $M$ is the total number of recorded pitch and roll readings. The nearest neighbour (NN) query was performed to estimate $\theta$ and $\phi$ as a function of the seed drop time $t$ by retrieving the $\theta_{j}$ and $\phi_{j}$ values belonging to the $t_{j}^{\prime \prime \prime}$ time that was nearest to the seed drop time $t$. The matching was done according to the minimum distance between $t_{j}^{\prime \prime \prime}$ and $t$ :

$$
j_{\mathrm{NN}}=\underset{j}{\arg \min }\left|t_{j}^{\prime \prime \prime}-t\right|
$$

Preliminary predictions of the pitch and roll at the seed drop event were then $\theta_{j}$ and $\phi_{j}$ for $j=j_{\mathrm{NN}}$, where $j_{\mathrm{NN}} \in\{1$, $\ldots, M\}$. To get more precise estimates of pitch and roll at the seed drop event, a linear regression was applied to pitch and roll values before and after the nearest neighbour dataset using the following two equations for $j=j_{\mathrm{NN}}$ :

$$
\begin{aligned}
& \theta_{[j-10, j+10]}=\omega_{\theta} \mathrm{UTC}_{[j-10, j+10]}+k_{\theta} \\
& \phi_{[j-10, j+10]}=\omega_{\phi} U T C_{[j-10, j+10]}+k_{\phi}
\end{aligned}
$$

The parameters of the linear regression models $\left(\omega_{\theta}, \omega_{\phi}, k_{\theta}, k_{\phi}\right)$ were estimated from data by least squares using a standard linear regression procedure of MATLAB ver. 6.5 (MathWorks, MA, USA). The linear regression models were used to determine the intermediate $\theta$ and $\phi$ values as a function of the seed drop time $t$. In order to link the actual pitch and roll angles to the GPS coordinate at the seed drop event, $t$ was transformed into a UTC time (Eq. (7)). Note that the regression parameters $\omega_{\theta}$ and $\omega_{\phi}$ represent angular velocities in radians s ${ }^{-1}$ at the actual seed drop event. The linear regression provides a low pass FIR filter that provided digital damping of noisy sensor output which was excited by sudden impulses in the high-vibration environment.

\subsubsection{Determination of seeder heading at each seed drop event}

Using the regression parameters $v_{X}$ and $v_{Y}$ estimated for a certain seed drop time in Eqs. (9) and (10), the direction $\psi^{\prime}$ in which the antenna was moving at seed drop time can be estimated as $\psi^{\prime}=a \tan ^{2}\left(v_{X}, v_{Y}\right) .{ }^{1}$ However, as illustrated

\footnotetext{
${ }^{1} a \tan ^{2}(x, y)$ computes inverse tangent of $y / x$, but uses the signs of both $x$ and $y$ to identify the quadrant in which the resulting angle lies. Heading angles in the world coordinate system range over a full $360^{\circ}$.
} 


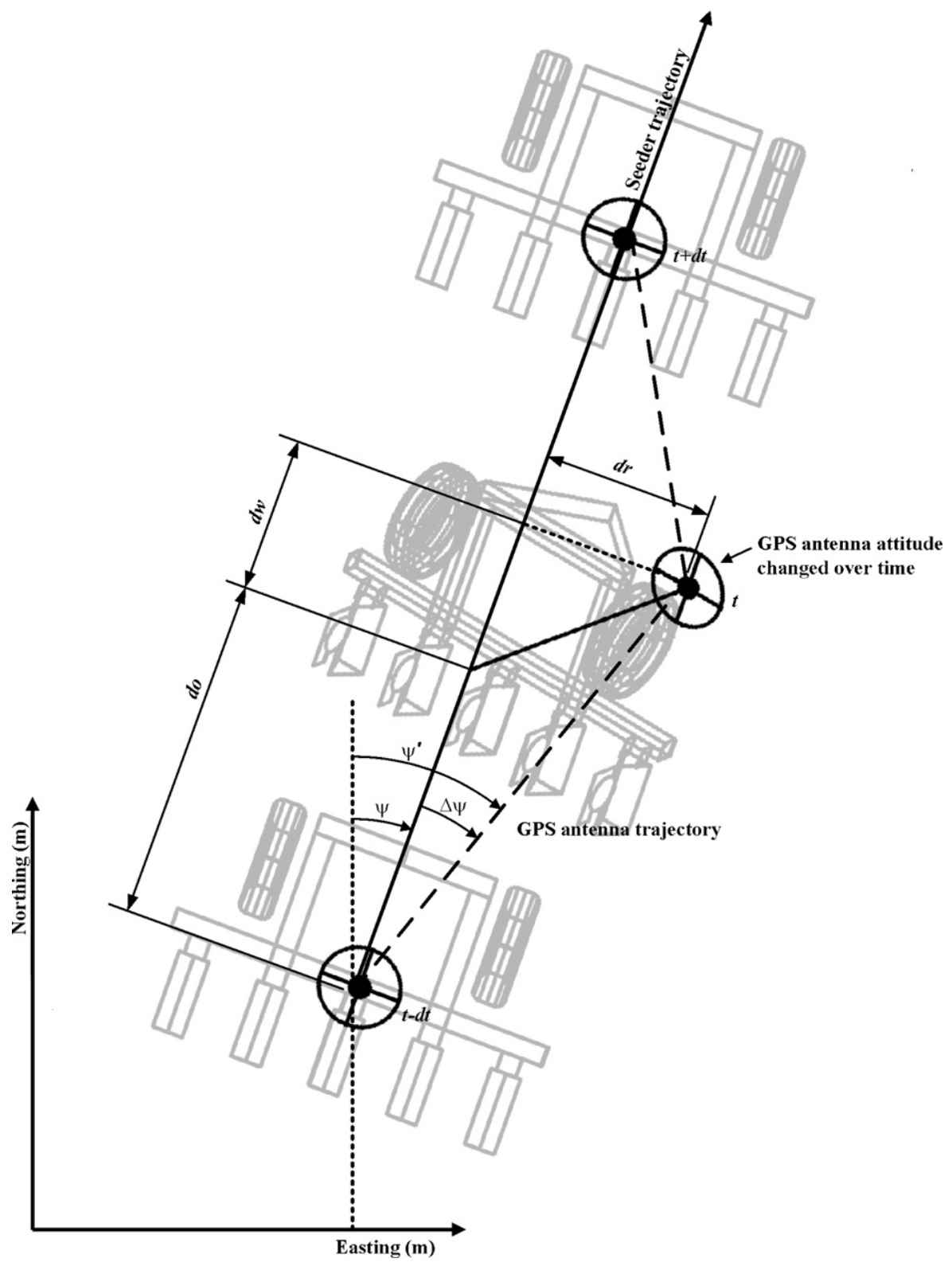

Fig. 3. Schematic drawing of the headings of the seeder and the GPS antenna in the global coordinate system (UTM). The drawing illustrates the seeder heading error $(\Delta \psi)$ caused by changes in pitch and roll.

in Fig. 3 the heading angle of the GPS antenna movement $\left(\psi^{\prime}\right)$ is only equal to the heading of the seeder in a situation where pitch and roll are constant. In a situation where $\theta$ and/or $\phi$ are changing when the seeder is moving forward with a constant heading, a difference $(\Delta \psi)$ between the seeder heading $\psi$ and the heading $\psi^{\prime}$ of the GPS antenna will occur (Fig. 3).

The determination of the seeder heading was given by:

$$
\psi=\psi^{\prime}-\Delta \psi
$$

To formulate the calculation of $\Delta \psi$, an infinitesimal period of time $\mathrm{d} t$ was considered. Over this time period, the seeder travels the distance $\mathrm{d} o$ in forward direction while the GPS antenna travels the distances $\mathrm{d} o+\mathrm{d} w$ and $\mathrm{d} r$ in directions parallel and perpendicular to the seeder trajectory, respectively (Fig. 3). By considering the right triangle 

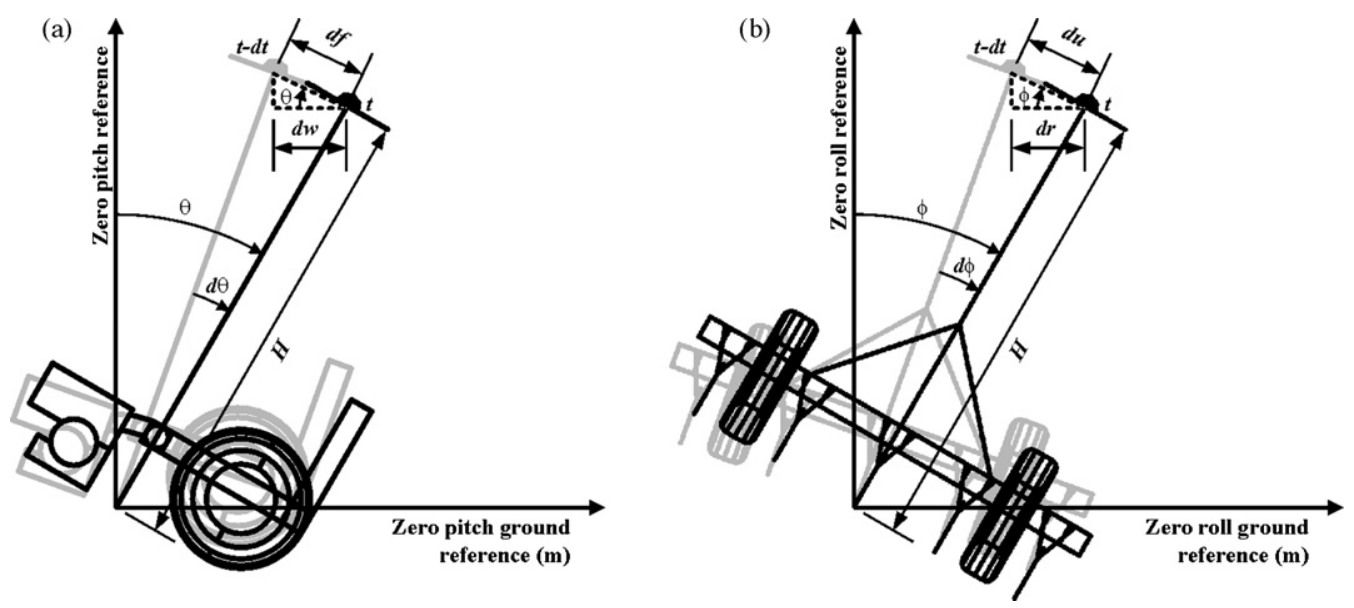

Fig. 4. (a) Side view of seeder, pitching forward with an angular velocity of $d \theta / d t$. (b) Rear view of seeder, rolling to the right with an angular velocity of $\mathrm{d} \phi / \mathrm{d} t$.

with legs of lengths $\mathrm{d} o+\mathrm{d} w$ and $\mathrm{d} r$, the following equation for $\Delta \psi$ is found:

$$
\Delta \psi=a \tan \left(\frac{\mathrm{d} r}{\mathrm{~d} o+\mathrm{d} w}\right)
$$

The distances $\mathrm{d} r, \mathrm{~d} o$ and $\mathrm{d} w(\mathrm{~m})$ can be derived from the pitch $(\theta)$, roll $(\phi)$, angular velocities $\left(\omega_{\theta}\right.$ and $\left.\omega_{\phi}\right)$, velocity of the seeder $(v)$ and GPS antenna height $(H)$ above ground level. The distance do can be derived from the velocity $(v)$ of the seeder:

$$
\mathrm{d} o=v \mathrm{~d} t
$$

The distance $\mathrm{d} w$ can be found by considering Fig. 4(a):

$$
\mathrm{d} w=\cos (\theta) \mathrm{d} f \quad \text { and } \quad \mathrm{d} f=H \mathrm{~d} \theta
$$

and thus

$$
\mathrm{d} w=H \cos (\theta) \mathrm{d} \theta
$$

or

$$
\frac{\mathrm{d} w}{\mathrm{~d} t}=H \cos (\theta) \omega_{\theta}
$$

The distances $\mathrm{d} r$ can be found by considering Fig. 4(b):

$$
\mathrm{d} r=\cos (\phi) \mathrm{d} u \quad \text { and } \quad \mathrm{d} u=H \mathrm{~d} \phi
$$

and thus

$$
\mathrm{d} r=H \cos (\phi) \mathrm{d} \phi
$$

or

$$
\frac{\mathrm{d} w}{\mathrm{~d} t}=H \omega_{\phi} \cos (\phi)
$$

When combining Eqs. (17)-(20), the following expression for $\Delta \psi$ (Fig. 3) is found:

$$
\Delta \psi=a \tan \left(\frac{H \omega_{\phi} \cos (\phi)}{v+H \omega_{\theta} \cos (\theta)}\right)
$$




\subsubsection{Determination of the global position at seed drop event}

This section presents the kinematic modelling of the seeder attitude in 3D based on Craig (2005). The seeder attitude is expressed in terms of the three Euler angles; roll, pitch and yaw. The kinematic model was introduced to combine global position $(X, Y)$ and altitude $(Z)$ of GPS antenna, seeder heading $(\psi)$ and tilt sensor data $(\theta, \phi)$ for estimation of the global position of the optical sensor at the seed drop event (i.e. the global position of the seed in the field).

Let $X Y Z$ be a right-handed, Cartesian, world coordinate system that gives the Universal Transverse Mercator (UTM) projected coordinates of the GPS antenna. Let $x y z$ be a right-handed, Cartesian, local coordinate system fixed to the seeder such that the origin coincides with the center of the GPS antenna, the $x$-axis pointing forward parallel to the seeder heading, the $y$-axis pointing right parallel to the seeder toolbar, and the $z$-axis pointing downwards perpendicular to the seeder toolbar and the seeder heading (JAUS, 2004). To locate the seed drop position in the world coordinate system, the 3D-positions in the local coordinate system of the optical sensors need to be determined. The positions of the six sensors in the local coordinate system are denoted as $x_{u}, y_{u}$, and $z_{u}(u=1, \ldots, 6)$. The values of $x_{u}, y_{u}$, and $z_{u}$ were determined by simple distance-measuring on the seeder.

A $z-y-x$ Euler angle rotation was first applied to rotate $x_{u}, y_{u}$, and $z_{u}$ in the local coordinate system about its origin (Craig, 2005). Secondly $x_{u}, y_{u}$, and $z_{u}$ was translated by a vector consisting of the GPS position $(X, Y, Z)$ at the seed drop event giving the sensor coordinates in the world coordinate system, $X_{u}, Y_{u}$, and $Z_{u}(u=1, \ldots, 6)$ at seed drop event. The rotation and translation can be formulated in matrix form as follows (Craig, 2005):

$$
\left[\begin{array}{c}
X_{u} \\
Y_{u} \\
Z_{u} \\
1
\end{array}\right]=\left[\begin{array}{cccc}
\cos (\psi) \cos (\phi) & \cos (\psi) \sin (\phi) \sin (\theta)+\sin (\psi) \cos (\theta) & \cos (\psi) \sin (\phi) \cos (\theta)-\sin (\psi) \sin (\theta) & X \\
-\sin (\psi) \cos (\phi) & \sin (\psi) \sin (\phi) \sin (\theta)+\cos (\psi) \cos (\theta) & -\sin (\psi) \sin (\phi) \cos (\theta)-\cos (\psi) \sin (\theta) & Y \\
\sin (\phi) & -\cos (\phi) \sin (\theta) & -\cos (\phi) \cos (\theta) & Z \\
0 & 0 & 0 & 1
\end{array}\right]\left[\begin{array}{c}
y_{u} \\
x_{u} \\
z_{u} \\
1
\end{array}\right]
$$

\subsection{Experimental procedure}

In order to investigate the performance of the instrumentation and the methodology during normal field sowing operations, two field experiments were carried out at two locations. The analysis was done for (i) target forward velocities of $2,3.6$ and $5 \mathrm{~km} \mathrm{~h}^{-1}$, and (ii) ratios between velocity of seeding disc rotation and forward velocity of 1.62 and 1.00 (i.e. zero horizontal velocity). The ratios corresponded to $125 \mathrm{~mm}$ and $202 \mathrm{~mm}$ seed spacing, respectively.

One field trial was carried out at the Research Centre Bygholm, Denmark, on April 16, $2003\left(55^{\circ} 51.87293^{\prime} \mathrm{N}\right.$, $\left.9^{\circ} 49.25270^{\prime} \mathrm{E}\right)$. A second field trial was done at the Copenhagen University research farm, Denmark, on April 24, $2003\left(55^{\circ} 40.16726^{\prime} \mathrm{N}, 12^{\circ} 18.52900^{\prime} \mathrm{E}\right)$. The trial plot and seedbed were prepared for sugar beet according to regional standards for sugar beet seeding. Both trial plots had plain soil surfaces, but had a minor downward declivity towards East $\left(<2^{\circ}\right)$. Visual assessment of the Copenhagen University research farm plot determined that big stones $(>50 \mathrm{~mm})$ occurred more frequently in one side of the experimental area. Seeds of sugar beet (Beta Vulgaris L.) cv. Magnum from Danisco Seeds were used.

The experiments included driving along eight straight tracks (both experiments) and a single curved track (only for the Copenhagen University research farm experiment). The intended length of the straight line tracks was $50 \mathrm{~m}$. The curved tracks consisted of an arc joining two points. The arc length was $14 \mathrm{~m}$ and was a portion of the circumference of a circle with radius $77 \mathrm{~m}$, giving a curvature with angular increments of $0.75^{\circ}$ per $1 \mathrm{~m}$ of driving. Surveying poles were established in the trial plots for the driver navigation along the desired tracks. The position of surveying poles was planned prior to establishment of the field experiments using Trimble Geomatics Office (Trimble Navigation Ltd., Sunnyvale, CA, USA). The surveying poles were placed in the field by use of RTK-GPS.

Prior to the recording of data in the field, the RTK-GPS positioning accuracy was verified. The procedure of the verification was performed by moving the GPS antenna from the seeder antenna pole to a tripod. The tripod was placed upon a benchmark with a known position. The position logging was performed for $1 \mathrm{~min}$ utilising the whole data acquisition system on the seeder. The verification procedure was also carried out after the recording of data in the field. The dual axis tilt sensor readings were also verified prior to recording of data in the field. The tilt sensor readings were recorded by the seeder data acquisition system and compared with readings from a standard Bosch DNM $60 \mathrm{~L}$ digital level (Bosch GmbH, Leinfelden-Echterdingen, Germany). 
During the seeding operations, data acquisition was started immediately after the tractor three-point linkage was lowered to start the seeding operation. At the end of the track, the seeder was lifted by the tractor three-point linkage to stop the seeding operation, at which time the data acquisition was also stopped.

\subsection{Performance analysis}

The determination of the performance of the data acquisition system and data processing methodology for estimation of plant positions was conducted when the sugar beet seedlings had emerged (BBCH $10-11$ ). The global position of the stem of emerged sugar beet seedlings was measured with RTK-GPS. The determination of the performance characteristics was done by calculating geometric distances between measured plant positions and the estimated seed positions. Data were analysed using standard statistical methods for mean and standard deviation, 95\% confidence interval for the variation and root mean square (RMS).

\section{Results and discussion}

In total, an area of 0.21 hectare was sown, and 23117 sugar beet seeds were registered by the optical sensors. When the seedlings had emerged, 810 plants ( $=3.5 \%$ of registered seeds) were used for the analysis of deviations between measured plant positions and corresponding seed drop positions, as estimated by the presented instrumentation and method. A graphical example of the geo-spatial mapping of individual sugar beet plants based on seed drop registration is shown in Figs. 5 and 6. Fig. 5 shows a photo of a plot consisting of 16 plants at the 6-8 leaf stage. The size of the frame delimiting the plot was $1.1 \mathrm{~m} \times 1.1 \mathrm{~m}$. In Fig. 6, the plants from Fig. 5 were geo-referenced using RTK-GPS in the field, thereby enabling the plant positions to be displayed in the world coordinate system. In Fig. 6, the circles indicate circular areas with a radius of $25 \mathrm{~mm}$ from the estimated seed positions. The circles show that all plants in this particular plot had emerged within a radius of $25 \mathrm{~mm}$ from the estimated seed positions.

To assess in more detail how the deviations between estimated seed positions and actual sugar beet positions arise, the error sources inherent in the presented instrumentation and methodology have to be considered. The errors involved were (i) RTK-GPS measurement error $\left(\varepsilon_{\mathrm{GPS}}\right)$, (ii) dual axis tilt sensor measurement error $\left(\varepsilon_{\text {tilt }}\right)$, (iii) seed displacement in the furrow after soil impact ( $\varepsilon_{\text {displacement }}$ ), and (iv) deviation between location of plant emergence and the corresponding seed location $\left(\varepsilon_{\text {seed-plant }}\right.$ ). It would be useful to combine the individual errors to obtain an expected total error. The mathematical model of the total deviation, $\varepsilon_{\text {tot }}$, between the estimated seed position and actual plant position is:

$$
\varepsilon_{\text {tot }}=\varepsilon_{\mathrm{GPS}}+\varepsilon_{\text {seed-plant }}+\varepsilon_{\text {displacement }}+\varepsilon_{\text {tilt }}
$$

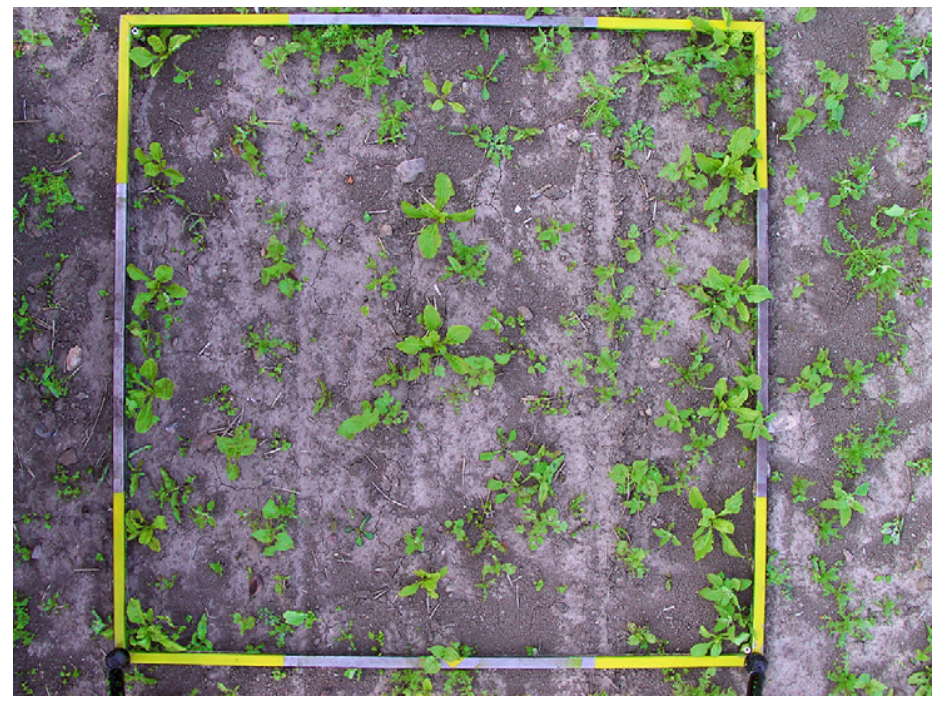

Fig. 5. Photo of a registration plot. 


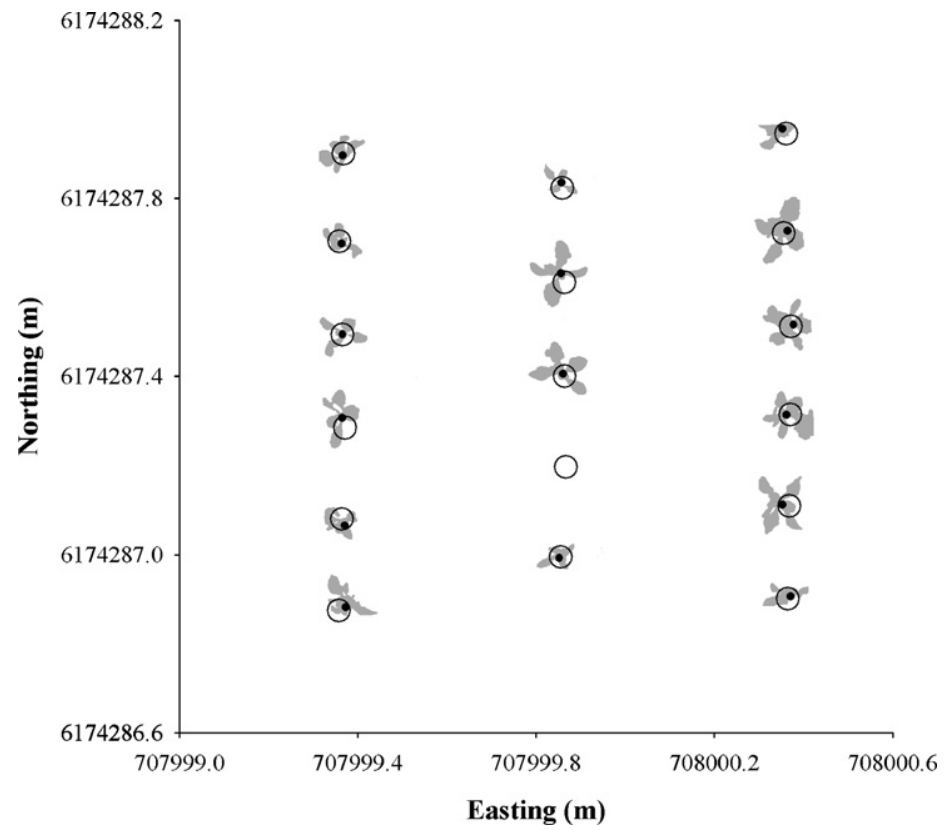

Fig. 6. Sketch of the registration plot from Fig. 5 located within the world coordinate system where the dots (O) indicate geo-referenced plant positions (measured at the main shoot of plants) and circles $(\bigcirc)$ indicate circular areas with a radius of $25 \mathrm{~mm}$ from estimated seed positions.

All errors in this equation are in millimeters at ground level. Eq. (23) should be used separately for longitudinal and transversal error relative to the driving direction.

The RMS of $\varepsilon_{\text {tot }}\left(\rho_{\text {tot }}\right)$ was used to quantify the error for plant position estimation. Based on Eq. (23), $\rho_{\text {tot }}$ can be determined using the following error propagation equation:

$$
\rho_{\text {tot }}=\sqrt{\rho_{\text {GPS }}^{2}+\rho_{\text {seed-plant }}^{2}+\rho_{\text {displacement }}^{2}+\rho_{\text {tilt }}^{2}}
$$

where $\rho_{\mathrm{GPS}}, \rho_{\text {seed-plant }}, \rho_{\text {displacement }}$ and $\rho_{\text {tilt }}$ are RMS values of $\varepsilon_{\mathrm{GPS}}, \varepsilon_{\text {seed-plant }}, \varepsilon_{\text {displacement }}$ and $\varepsilon_{\text {tilt }}$, respectively. Eq. (24) assumed independency between the error terms.

In Eq. (24), $\rho_{\mathrm{GPS}}$ is the RTK-GPS measurement accuracy. The RTK-GPS equipment used in this study has previously been investigated in a 24-hour benchmark trial (Nørremark et al., 2003). The 24-h RTK-GPS static trial was done to reveal the system accuracy. Positions were logged at $10 \mathrm{~s}$ intervals for $24 \mathrm{~h}$. The obtained RMS of the RTK-GPS system was $9.5 \mathrm{~mm}$.

The soil conditions of a field have an influence on where plants emerge related to their seed location. Quantification of deviations caused by varying soil type and seedbed conditions has been done (Griepentrog et al., 2005). Deviation data from this study for sandy loam soil type and fine seed bed were analyzed in this paper for mean and standard deviation, $0.8 \mathrm{~mm} \pm 12.4 \mathrm{~mm}\left(\rho_{\text {seed-plant }}=12.4 \mathrm{~mm}\right)$. Seedbed conditions provided the largest error contribution to the estimation of plant positions from seed positions. These fully random errors will always occur because they appear due to normal and unavoidable soil structure conditions.

Random errors from longitudinal seed displacement (e.g. seed bouncing) occur after seed impact with the furrow. Bufton et al. (1974) analysed the relationship between the longitudinal seed displacement in V-shaped furrows and the angle between seed trajectory and horizontal plane of the furrow, the so called seed impact angle. Bufton et al. (1974) found that a seed impact angle of $80^{\circ}$, which is $10^{\circ}$ off vertically seed drop, contributes to longitudinal seed displacements of $7.2 \mathrm{~mm} \pm 4.6 \mathrm{~mm}$ S.D. (RMS $8.5 \mathrm{~mm}$ ) at forward velocity of $4.5 \mathrm{~km} \mathrm{~h}^{-1}$. Therefore, the error estimate of seed displacement in the furrow ( $\rho_{\text {displacement }}$ ) was set to $8.5 \mathrm{~mm}$ RMS for the seeder used in this research. This error estimate was related to the $202 \mathrm{~mm}$ seed spacing settings of the seeder where it is assumed that the seeds drop almost vertically into the $\mathrm{V}$-shaped furrow.

An assessment using the dual axis tilt sensor in a high-vibration environment was performed to estimate $\rho_{\text {tilt }}$. Fig. 7 shows the measured pitch data, before and after FIR filtering. The mean \pm S.D. was $0.03^{\circ} \pm 6.22^{\circ}$ and $-0.02^{\circ} \pm 0.49^{\circ}$, 


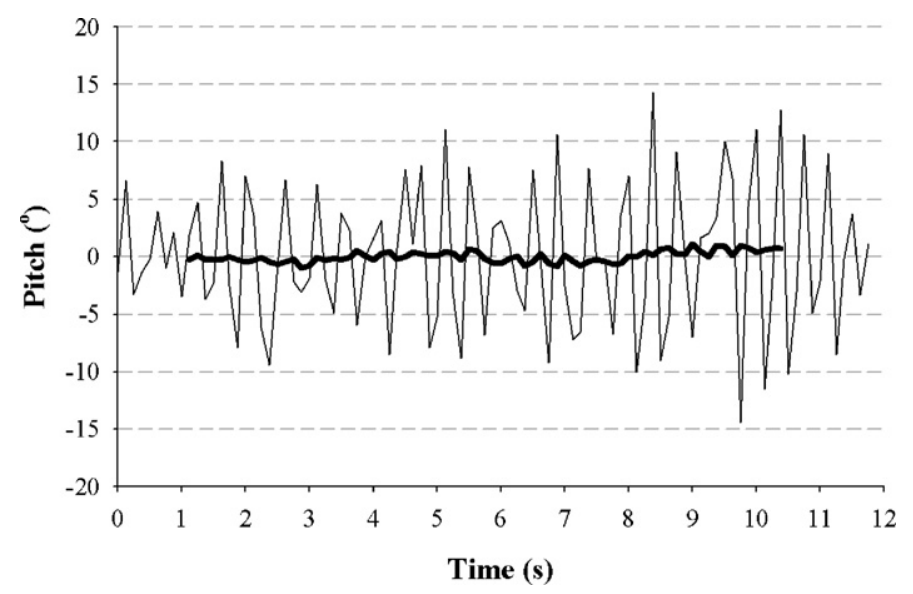

Fig. 7. Pitch data: Bold line, pitch data after filtering; Slim line, pitch data before filtering.

respectively. Thus, the RMS of the filtered pitch measurements was $0.49^{\circ}$, corresponding to an RMS at ground level of $\rho_{\text {tilt }}=9.8 \mathrm{~mm}\left(\sin \left(0.49^{\circ}\right) \times\right.$ antenna height $)$.

RMS values for the deviations between estimated seed positions and actual plant positions are summarised in Table 1. The result of using Eq. (24) is found to be $\rho_{\mathrm{tot}}=20.3 \mathrm{~mm}$ for the error longitudinal to the direction of driving and $\rho_{\text {tot }}=18.4 \mathrm{~mm}$ for the error transversal to the direction of driving.

Table 2 summarises the mean, RMS and the confidence interval for the variation of the deviation between estimated seed positions and measured plant positions in the North-South and East-West directions. The field experiments were planned and placed for driving in the North-South and East-West directions. That introduced the possibility of investigating numerous error parameters. One is how the different seed spacing resulted in biased mean deviation. A second is how the seeder attitude influenced the mean deviation. The normalized RMS values in Table 2 are either below or almost equal to the expected total RMS error for the presented instrumentation and methodology (Table 1) for $202 \mathrm{~mm}$ (both directions) and $125 \mathrm{~mm}$ seed spacing (only East-West direction, i.e. transversal of driving direction). Very consistent results were obtained from experiments while the seeder was adjusted for $202 \mathrm{~mm}$ seed spacing and was travelling at velocities between 2 and $5 \mathrm{~km} \mathrm{~h}^{-1}$, as shown in Table 2 (track A to G). However, RMS of the distance between seed drop positions and plant positions for $125 \mathrm{~mm}$ seed spacing in the North-South driving direction showed a clear bias (track $\mathrm{H}$ to $\mathrm{K}$ ). When the seed spacing was $125 \mathrm{~mm}$ and the seeder was driving North, the seed was placed south of the registered seed drop position and vice versa for the South driving direction. This bias was most noticeable for high forward velocities (track $\mathbf{J}$ and $\mathrm{K}$ ). The bias was a consequence of seeds being thrown backwards into the furrow before soil covering. At a seed spacing of $125 \mathrm{~mm}$ spacing the seeds was released from the seeding disc with a

Table 1

Sources of uncertainty affecting the estimated crop plant positions

\begin{tabular}{llc}
\hline Error sources & \multicolumn{2}{l}{ Magnitude of RMS error $(\mathrm{mm})$} \\
\cline { 2 - 3 } & Longitudinal of driving direction & Transversal of driving direction \\
\hline RTKGPS accuracy $\left(\rho_{\mathrm{GPS}}\right)$ & 9.5 & 9.5 \\
Dual axis tilt sensor in high-vibration environment $\left(\rho_{\text {tilt }}\right)$ & $9.8^{\mathrm{a}}$ & 9.8 \\
$\begin{array}{l}\text { Displacements of seeds in the furrows after passing the } \\
\quad \text { optical sensors }\left(\rho_{\text {displacement }}\right)\end{array}$ & $8.5^{\mathrm{b}}$ & $0.0^{\mathrm{c}}$ \\
Deviation of plant positions from seed positions $\left(\rho_{\text {seed-plant }}\right)$ & 12.4 & 12.4 \\
Error propagation result $\left(\rho_{\text {tot }}\right)$ & 20.3 & 18.4 \\
\hline
\end{tabular}

\footnotetext{
${ }^{\mathrm{a}}$ Based on the RMS of measured tilt angle errors (RMS $=0.49^{\circ}$ ). With the GPS antenna placed $1.15 \mathrm{~m}$ above ground level, this tilt error RMS is resulting in an RMS of $9.8 \mathrm{~mm}$ at ground level.

b Measured for impact angle of $80^{\circ}$ and seed velocity of 1.6 times the seed velocity accelerated by gravity alone. Based on numbers from Bufton et al. (1974).

c The lateral seed distribution is insignificant. In general its coefficient of variation is below 4\% (Heege and Billot, 1999).
} 
Table 2

Results and statistics for distances between estimated seed drop positions and measured plant positions

\begin{tabular}{|c|c|c|c|c|c|c|c|c|c|c|c|}
\hline \multirow[t]{2}{*}{ Track } & \multirow{2}{*}{$\begin{array}{l}\text { Seed spacing } \\
(\mathrm{mm})\end{array}$} & \multirow{2}{*}{$\begin{array}{l}\text { Average speed } \\
\left(\mathrm{km} \mathrm{h}^{-1}\right)\end{array}$} & \multirow{2}{*}{$\begin{array}{l}\text { Driving } \\
\text { direction }\end{array}$} & \multirow[t]{2}{*}{ PDOP } & \multirow{2}{*}{$\begin{array}{l}\text { No. of } \\
\text { Plants }\end{array}$} & \multicolumn{3}{|c|}{ North-South distance $(\mathrm{mm})^{\mathrm{a}}$} & \multicolumn{3}{|c|}{ East-West distance $(\mathrm{mm})^{\mathrm{b}}$} \\
\hline & & & & & & Mean & $\pm \Delta_{95 \%}{ }^{c}$ & RMS & Mean & $\pm \Delta_{95 \%}{ }^{\mathrm{e}}$ & RMS \\
\hline $\mathrm{A}^{\mathrm{d}}$ & 202 & 3.31 & East & 2.2 & 55 & -2.7 & \pm 19.9 & 10.5 & 1.3 & \pm 24.0 & 12.3 \\
\hline$B^{d}$ & & 3.84 & West & 2.9 & 42 & 0.7 & \pm 24.5 & 12.5 & 1.5 & \pm 27.0 & 13.8 \\
\hline$C^{d}$ & & 3.11 & Random & 2.6 & 17 & -1.2 & \pm 26.7 & 13.7 & -5.7 & \pm 25.8 & 14.3 \\
\hline $\mathrm{D}^{\mathrm{e}}$ & 202 & 2.05 & Curved & 2.4 & 43 & -5.4 & \pm 25.9 & 14.3 & 7.0 & \pm 16.6 & 11.0 \\
\hline $\mathrm{E}^{\mathrm{e}}$ & & 2.25 & North & 3.3 & 80 & -9.2 & \pm 28.1 & 17.0 & 0.3 & \pm 16.1 & 8.2 \\
\hline $\mathrm{F}^{\mathrm{e}}$ & & 4.88 & North & 2.1 & 80 & -7.4 & \pm 27.3 & 15.8 & 0.5 & \pm 27.3 & 14.0 \\
\hline $\mathrm{G}^{\mathrm{e}}$ & & 5.33 & South & 2.8 & 45 & 9.4 & \pm 22.8 & 15.0 & 5.4 & \pm 20.9 & 11.9 \\
\hline $\mathrm{H}^{\mathrm{e}}$ & 125 & 2.14 & North & 4.5 & 117 & 17.6 & \pm 43.8 & 28.5 & 1.2 & \pm 24.2 & 12.4 \\
\hline $\mathrm{I}^{\mathrm{e}}$ & & 2.35 & South & 4.2 & 112 & -1.7 & \pm 26.6 & 13.7 & 1.8 & \pm 19.0 & 9.9 \\
\hline $\mathrm{J}^{\mathrm{e}}$ & & 4.92 & North & 3.9 & 108 & 39.8 & \pm 27.2 & 42.1 & 3.3 & \pm 22.6 & 12.0 \\
\hline $\mathrm{K}^{\mathrm{e}}$ & & 5.05 & South & 3.6 & 111 & -28.0 & \pm 26.5 & 31.2 & 10.7 & \pm 29.9 & 18.6 \\
\hline
\end{tabular}

The nominal seed spacing, driving speed and direction, position dilution of precision (PDOP) and the number of plants used for the evaluation are indicated.

${ }^{a}$ Signed distances: a positive distance means that the plant was found South of the seed drop position and vice versa.

b Signed distances: a positive distance means that the plant was found West of the seed drop position and vice versa.

c $\Delta_{95 \%}$ indicates the $95 \%$ confidence interval for the distance observations assuming a normal distribution.

${ }^{\mathrm{d}}$ Research Centre Bygholm field experiment.

e Copenhagen University farm field experiment.

relative horizontal velocity higher and opposite to the vehicle's forward velocity. The velocity of the seed being thrown is dependent on the ratio between forward velocity and the seed disc rotational velocity. At a seed spacing of $125 \mathrm{~mm}$, the seed disc velocity is 1.616 times the forward velocity. At a forward velocity of $5 \mathrm{~km} \mathrm{~h}^{-1}$ the seed will have an initial horizontal velocity of $3.08 \mathrm{~km} \mathrm{~h}^{-1}\left(0.616 \times 5 \mathrm{~km} \mathrm{~h}^{-1}\right)$. Suppose that the seed trajectory (from seed disc release to impact with the furrow) can be described by a parabolic trajectory, when air resistance is ignored. Fig. 8 shows the seed trajectory for $125 \mathrm{~mm}$ seed spacing at forward velocity of 2 and $5 \mathrm{~km} \mathrm{~h}^{-1}$ and for $202 \mathrm{~mm}$ seed spacing at $5 \mathrm{~km} \mathrm{~h}^{-1}$ from a fall height of $30 \mathrm{~mm}$ (i.e. the distance from optical sensor to furrow bottom).

Assuming that the seed trajectory is influenced by gravity and its initial velocity and direction, the longitudinal deviation will in theory be $30.3 \mathrm{~mm}$ and $18.1 \mathrm{~mm}$ at 5 and $2 \mathrm{~km} \mathrm{~h}^{-1}$ forward velocity, respectively, for seed spacing of $125 \mathrm{~mm}$ (Fig. 8). That explains some of the bias observed in Table 2 for the trials with $125 \mathrm{~mm}$ seed spacing. However, there are exceptions for this theory, especially for track I. Track I and H are both different from the pattern of track $\mathrm{J}$ and $\mathrm{K}$ in terms of bias and confidence interval of variation, thus, giving unexpected results. The difference that can

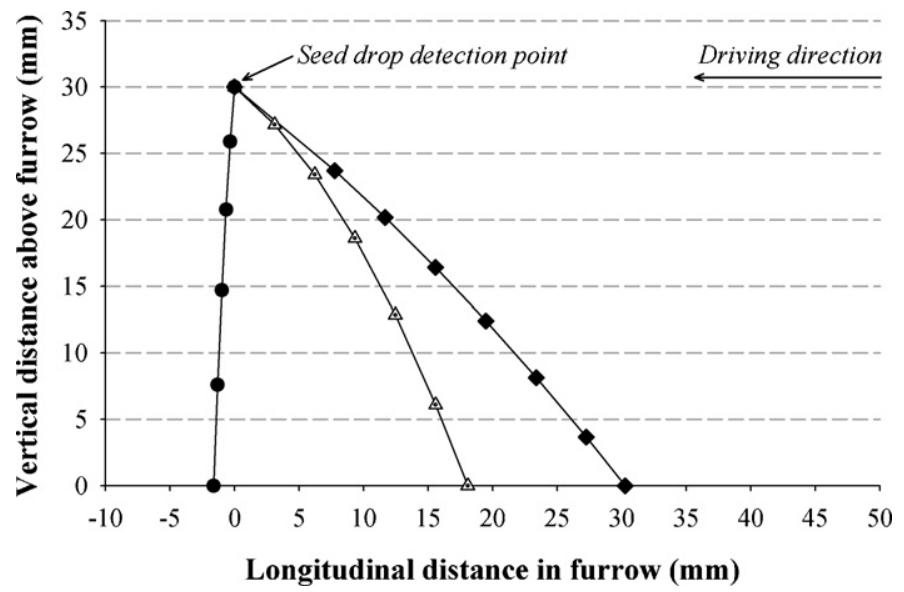

Fig. 8. Seed trajectories from release of seed until impact with furrow bottom for; seed spacing of $202 \mathrm{~mm}$ and forward velocity of $5 \mathrm{~km} \mathrm{~h}^{-1}()_{)}$; seed spacing of $125 \mathrm{~mm}$ and forward velocity of $2 \mathrm{~km} \mathrm{~h}^{-1}(\triangle)$ and $5 \mathrm{~km} \mathrm{~h}^{-1}(\diamond)$. 
Table 3

Comparisons of errors in predicted sugar beet positions with and without utilisation of pitch and roll data for heading correction and rotational coordinate transformation

\begin{tabular}{|c|c|c|c|c|c|c|c|c|}
\hline \multirow[t]{2}{*}{ Data processing settings } & \multirow[t]{2}{*}{$\begin{array}{l}\text { Driving } \\
\text { direction }\end{array}$} & \multirow[t]{2}{*}{$\begin{array}{l}\text { No. of } \\
\text { plants }\end{array}$} & \multicolumn{2}{|c|}{$\begin{array}{l}\text { North-South distances }{ }^{\mathrm{a}} \\
(\mathrm{mm})\end{array}$} & \multirow[t]{2}{*}{$t^{\mathrm{b}}$} & \multicolumn{2}{|c|}{$\begin{array}{l}\text { East-West distances }^{\mathrm{c}} \\
(\mathrm{mm})\end{array}$} & \multirow[t]{2}{*}{$t^{\mathrm{b}}$} \\
\hline & & & Mean & \pm S.D. & & Mean & \pm S.D. & \\
\hline \multirow[t]{2}{*}{ Utilisation of pitch and roll data } & North & 80 & -7.4 & \pm 13.9 & - & 0.5 & \pm 13.9 & - \\
\hline & South & 45 & 9.4 & \pm 11.6 & - & 5.4 & \pm 10.6 & - \\
\hline \multirow[t]{2}{*}{ No utilisation of pitch and roll data } & North & 80 & -7.5 & \pm 11.9 & 0.03 N.s. & 29.5 & \pm 12.4 & $-13.91^{* * *}$ \\
\hline & South & 45 & -15.7 & \pm 14.2 & $9.16^{* * *}$ & 14.8 & \pm 10.3 & $-4.25^{* * *}$ \\
\hline
\end{tabular}

\footnotetext{
a A positive distance means that the plant was found South of the seed drop position and vice versa.

b Student's $t$-test: ${ }^{* * *} P<0.001$, N.s.: not significant.

c A positive distance means that the plant was found West of the seed drop position and vice versa.
}

explain the confidence interval of variation for track $\mathrm{H}$ is seedbed conditions. Track $\mathrm{H}$ was unfortunately placed on an unfavourable area where stones $(>50 \mathrm{~mm})$ occurred more frequently than in the other tracks. It was observed that the stones confer more rapid and larger vertical movements of the seeder units. That increases the likelihood for variation of longitudinal seed displacement in the furrow as seen for track $\mathrm{H}$. The confidence interval of variation for track I was not different from the other tracks, but the bias was smaller than the expected $18.1 \mathrm{~mm}$ inherent from the longitudinal seed displacement (Fig. 8). The mean deviation between measured and estimated plant positions was not more than $9.4 \mathrm{~mm}$ (track G), resulting from field trial data operation velocities up to $5.3 \mathrm{~km} \mathrm{~h}^{-1}$ and for $202 \mathrm{~mm}$ seed spacing only. Furthermore, the $95 \%$ confidence interval of the deviations between measured and estimated plant positions was not more than $\pm 28.1 \mathrm{~mm}$ (track E). Taking the worst case of all experiments with $202 \mathrm{~mm}$ seed spacing (track E, North-South distance) and with $95 \%$ probability, a plant can be found within a radius of not more than $37.3 \mathrm{~mm}$ from the geo-referenced seed.

The conducted field experiments were also used for the investigation of how the seeder attitude affected the accuracy of the predicted sugar beet positions. Raw data acquired during seeding of track F and G were used for this investigation. Table 3 shows that inclusion of observed attitude data in the data processing (i.e. Eqs. (21) and (22)) provided significantly better accuracy than having $\theta=\phi=\omega_{\theta}=\omega_{\phi}=0$ in the same equations.

The investigation of setting pitch and roll to zero was done by exclusion of heading correction, thus using the uncorrected heading of the GPS antenna directly and by setting pitch and roll to zero in the Euler angle rotation and translation matrix (Eq. (22)). Consequently, the investigation showed only significance in situations where pitch and roll were different from zero. Thus, there was no significant difference for North-South distances from the North driving direction, because the registered pitch data during seeding at the analysed field experimental plots were only $0.03^{\circ}$ on average.

\section{Conclusions}

The research investigated the technological basis for producing geo-spatial maps of individual sugar beet seeds from data acquired during seeding operations. The instrumentation and methodology consisting of a precision seeder retrofitted with RTK-GPS, a dual axis tilt sensor, seed drop sensors, a data acquisition system and data processing algorithms have been developed and validated. Field trials verified that the system could reliably estimate crop plant positions. With $95 \%$ probability, a crop plant could be found within a radius of not more than $37.3 \mathrm{~mm}$ from its geo-referenced seed. This was obtained for operation velocities up to $5.3 \mathrm{~km} \mathrm{~h}^{-1}$ and for $202 \mathrm{~mm}$ seed spacing only.

The $37.3 \mathrm{~mm}$ could be considered as the radius of demarcated areas where crop plants will appear. These sub-areas of a field ( $100.000 \mathrm{ha}^{-1}$ for sugar beet) are then the target areas, for e.g. technologies to apply treatments to individual sugar beet seedlings or the areas where tillage or other physical weeding principles should not be applied. Furthermore, the $37 \mathrm{~mm}$ also determine the distance from crop row centre (determined by estimated seed position) to the outer limits of the row band width. Hence, in case navigation is based on seed map, guidance of vehicles and/or tillage implements parallel to crop rows cannot be done closer to row centre than these limits in order to minimise the risk of crop damage. 
From the error analysis, it can be concluded that the errors associated with the estimation of plant position consist of positioning sensor measurement errors, seed displacement in the furrow and deviation between location of plant emergence and the corresponding seed location. Furthermore, it can be concluded that the error contribution from individual sources is of the same magnitude, except for the error due to deviation between the location of plant emergence and the corresponding seed location. As this fully random error will always occur, it is considered meaningless trying to further minimise the sensor errors.

Inclusion of seeder attitude data (i.e. tilt data) in the data processing provided significantly better accuracy of the estimation of plant positions and therefore it is concluded that a dual axis tilt sensor is a required part of the instrumentation. Furthermore, obtaining zero horizontal velocity of the seed when released from the seeding mechanism, or after seed drop registration, was also required to achieve high accuracy of the estimation of geo-referenced plant positions.

Although the presented instrumentation and method could be capable of creating a geo-spatial map of seeds of other crops, this research validated the system only with sugar beet. Validating the applicability of the developed system for other crops is an interesting challenge for further investigations.

\section{Acknowledgements}

This work was funded by the Danish Research Centre for Organic Farming with additional support from Kverneland Company, who supported the project with their equipment. Thanks to Professor Simon Blackmore for advisory support and to Peter Rasmussen who supported the MatLab programming. Thanks to Hanne Lipczak Jakobsen from the Copenhagen University research farm and to Peter Storegaard Nielsen from the Research Centre Bygholm farm for providing assistance in connection to the field experiments.

\section{References}

Andersen, H.J., Ring, L., Kirk, K., 2005. Geometric plant properties by relaxed stereo vision using simulated annealing. Comput. Electron. Agric. 49, 219-242.

Bak, T., Jacobsen, H., 2004. Agricultural robotic platform with four wheel steering for weed detection. Biosyst. Eng. 87, $125-136$.

Blackmore, S.B., Stout, B., Wang, M., Runov, B., 2005. Robotic agriculture. In: Stafford, J. (Ed.), Proceedings of the 5th European Conference on Precision Agriculture. Uppsala, Sweden.

Blasco, J., Aleixos, N., Roger, J.M., Rabatel, G., Moltó, E., 2002. Robotic weed control using machine vision. Biosyst. Eng. 83, $149-157$.

Bufton, L.P., Richardson, P., O’Dogherty, M.I., 1974. Seed displacement after impact on a soil surface. J. Agric. Eng. Res. 19, $327-338$.

Cho, S.I., Chang, S.J., Kim, Y.Y., An, K.J., 2002. Development of a three-degrees-of-freedom robot for harvesting lettuce using machine vision and fuzzy logic control. Biosyst. Eng. 82, 143-149.

Craig, J.J., 2005. Introduction to robotics - Mechanics and control. Pearson Prentice Hall, Upper Saddle River, NJ, USA.

Ehsani, M.R., Upadhyaya, S.K., Mattson, M.L., 2004. Seed location mapping using RTK-GPS. Trans. ASAE 47, 909-914.

Griepentrog, H.W., 2001. EKS - statistical software to analyse seed or plant spacing. The Royal Veterinary and Agricultural University, Department of Agricultural Sciences, Taastrup, Denmark.

Griepentrog, H.W., Nørremark, M., Nielsen, H., Blackmore, B.S., 2003. Individual plant care in cropping systems. In: Stafford, J.V., Werner, A. (Eds.), Proceedings of the 4th European Conference on Precision Agriculture. Berlin, Germany.

Griepentrog, H.W., Christensen, S., Søgaard, H.T., Nørremark, M., Lund, I., Graglia, E., 2004. Robotic weeding. In: Proceedings of AgEng 2004 Engineering The Future, Leuven, Belgium.

Griepentrog, H.W., Nørremark, M., Nielsen, H., Blackmore, B.S., 2005. Seed mapping of sugar beet. Precision Agric. 6, 157-165.

Grundy, A.C., Onyango, C.M., Phelps, K., Reader, R.J., Marchant, J.A., 2005. Using a competition model to quantify the optimal trade-off between machine vision capability and weed removal effectiveness. Weed Res. 45, 388-405.

Heege, H.J., Billot, J.F., 1999. Seeders and Planters. In: Stout, B.A. (Ed.), CIGR Handbook of Agricultural Engineering, vol. 3. Plant Production Engineering. American Society of Agricultural Engineers, St. Joseph, MI, USA.

JAUS, 2004. Platform Orientation. Reference Architecture Specification. Version 3.2, vol. 2, part 2, The Joint Architecture for Unmanned Systems, Office of the Under Secretary of Defense for Acquisition, Technology and Logistics, Washington DC, USA, online at http://www.jauswg.org/baseline/RA\%20V3-2\%20Part\%202.doc (last assessed 30 March, 2006).

Kise, M., Zhang, Q., Rovira Más, F., 2005. A stereovision-based crop row detection method for tractor-automated guidance. Biosyst. Eng. 90, 357-367.

Lee, W.S., Slaughter, D.C., Giles, D.K., 1999. Robotic weed control system for tomatoes. Precision Agric. 1, 95-113.

Melander, B., Rasmussen, G., 2001. Effects of cultural methods and physical weed control on intra-row weed numbers, manual weeding and marketable yield in direct-sown leek and bulb onion. Weed Res. 41, 491-508.

Nørremark, M., Griepentrog, H.W., Nielsen, H., Blackmore, B.S., 2003. A method for high accuracy geo-referencing of data from field operations. In: Stafford, J.V., Werner, A. (Eds.), Proceedings of the 4th European Conference on Precision Agriculture. Berlin, Germany. 
Padel, S., Lampkin, N., 1994. Conversion to organic farming: an overview. In: Lampkin, N.H., Padel, S. (Eds.), The Economics of Organic Farming: An International Perspective. CAB International, Wallingford, Oxon, UK.

Srivastava, A.K., Goering, C.E., Rohrbach, R.P., 1993. Engineering Principles of Agricultural Machines. American Society of Agricultural Engineers, St. Joseph, MI, USA.

Søgaard, H.T., 2005. Weed classification by active shape models. Biosyst. Eng. 91, 271-281.

Søgaard, H.T., Nørremark, M., 2004. Robotic localisation of sugar beets by use of RTK-GPS, computer vision and seed maps. In: Proceedings of AgEng 2004, Leuven, Belgium.

Sørensen, C.G., Madsen, N.A., Jacobsen, B.A., 2005. Organic farming scenarios: operational analysis and costs of implementing innovative technologies. Biosyst. Eng. 91, 127-137.

Trimble, 1999. Trimble MS750 Operation Manual Revision B. Part no. 36574-00. Trimble Navigation Ltd., Sunnyvale, CA, USA.

Van Zuydam, R.P., Sonneveld, C., Naber, H., 1995. Weed control in sugar beet by precision guided implements. Crop Prot. 14, 335-340. 